\title{
Accounting for the Extractive Industries: Controversies and a Need for Harmonisation
}

\author{
Hafez Abdo \\ Department of Accounting and Finance, Nottingham Business School, UK
}

Article history

Received: 19-05-2018

Revised: 7-08-2018

Accepted: 27-08-2018

Email:hafez.abdo@ntu.ac.uk

\begin{abstract}
The oil and gas industry is international in nature and being operated, in most, by multinational companies. However, accounting for the activities of the oil and gas industry is being practiced by using different methods. These methods produce incomparable results which makes it hard for users of thes companies' accounts to make investments decissions. In this paper, we demonstrate the differences in accounting practices by oil and gas industry via an extensive literature review. Historically, there has been a number of attempts by accounting bodies to harmonise accounting practices by extractive industries, howeever these attempts have not been successful. We highlight the historical controversies sourounding accounting for the oil and gas industry and we make a call on the International Accounting Standard Board to produce a comprehensive accounting standard for the extractive industries in general, and the oil and gas industry in particular. Such a standard would unify accounting practices by oil and gas companies and act as a common language that companies use when preparing their accounts.
\end{abstract}

Keywords: Accounting, Controversies, Full Cost, IASB, Oil and Gas

\section{Introduction}

Background

Oil and gas industry has globalised aspects, and due to its cross border activities, is an international industry in nature. Given its special characteristics in terms of its social and political aspects and public perceptions of its activities the oil and gas industry is fundamentally different from the other extractive industries (Russell and Jenkins, 2010; Nichols and Linda, 2012). According to BP Statistical Review (2017), in 2016 the World oil production was 4,382.4 million tonnes (Mtn), oil consumption equalled to $4,418.2 \mathrm{Mtn}$. Whilst a simple comparison of these figures depicts that oil consumption exceeded oil production, a more sophisticated approach reveals the importance of the oil and gas industry to the World economies. In terms of revenues, a number of oil and gas companies sit in the top 10 world largest corporations. For example, China Natural Petroleum is the fourth largest company in the world with an annual revenue of \$262.6bn, Royal Dutch Shell is the seventh with an annual revenue of $\$ 240 \mathrm{bn}$ and Exxon Mobil is the tenth with an annual revenue of \$205bn (Christie, 2017). These simple statistics shed light on the significance of the oil and gas industry. Consequently, it necessitates some clear, unified and transparent accounting system to be in place for an ease of understanding by users for comparability and decision making purposes.

This article, via literature review, highlights the differences in accounting for extractive industries, with focus on oil and gas industry. It uncovers the controversies in accounting for the extractive industries and presents a need for a comprehensive accounting standard that harmonises accounting practices by oil and gas companies in particular and extractive industries in general. Accounting for oil and gas industry, besides being complicated, uses different methods. The variety of methods leads to incomparable accounting figures. This makes it difficult for stakeholders to make investment decisions. Therefore, the International Accounting Standard Board (IASB) is required to develop a comprehensive accounting standard for the oil and gas industry. Such standard requires international acceptance and implementation in order to achieve the comparability objective of financial statements of oil and gas companies. The remaining of this paper is organised as follows: the next section discusses accounting methods for extractive industries, section 3 discusses debates of the differences 
between the two main accounting methods used by the extractive industries: successful methods and full cost; section 4 presents method choice effects and the need for harmonized accounting treatment and section 5 presents concluding remarks.

\section{Accounting Methods for the Extractive Industries}

In accounting for investments in the extractive industries as discussed above, oil and gas companies have the option to choose among a number of methods, but the most common are the successful efforts method and the full cost method (Flory and Grossman, 1978; Cortese et al., 2009). These two methods differ as to which Exploration and Evaluation (E\&E) expenditures are capitalized; in other words, the interpretation of the "tells it like it is" concept differs between these two accounting methods. Capitalising or expensing unsuccessful E\&E costs can have significant impact on the assets book value and reported profits by companies (Johnson and Ramanan, 1988; Abdo et al., 2017), particularly for entities at the exploration stage of their investments (PwC, 2017). This has historically led to a significant controversy in the accounting literature over which of the two commonly used methods captures the underlying economic transaction (Bryant, 2003). In general, this controversy relates (Flory and Grossman, 1978), to both the physical attributes of mineral resource production and the financial impacts on the extractive industries. A third dimension of this controversy is, according (Van Riper, 1994), regulatory and political interference in the accounting profession tasks. The next sections discuss these two methods in some details, this is followed by discussion of accounting method choice.

\section{The Successful Efforts Method}

According to the Successful Efforts (SE) method, costs that can be assigned to successful discoveries that have commercial viability are capitalized on a field-byfield basis; other costs are generally charged to expenses. These capitalized costs are Depreciated, Depleted and Amortized (DD\&A) over the estimated economic life of a given project on a field-by-field basis as production occurs (PwC, 2017; Bryant, 2003; Noël et al., 2010; Ernst \& Young, 2009). If the outcome of the discoveries is unknown, the operation costs are recorded in a holding account as work-in-progress/intangible assets and are then capitalized when the outcome of the operation is a success; otherwise, they should be expensed (Dyckman and Smith, 1979; Gallun et al., 2001). Thus, the SE method considers only those costs related to successful production as relevant to the generation of future revenues, while costs relating to unsuccessful production are considered expenses in the period in which they have incurred. Existing evidence reveals that larger, integrated and well-established extractive companies generally use this method of accounting (Flory and Grossman, 1978). This is because, due to their financial capabilities, writing off costs of unsuccessful explorations for these companies does not significantly influence their reported performance. Most (1979) claims that the SE method aligns with the income tax laws with regard to allowable expenditure hence is favorable by companies that have the desire to confirm their accounting records as closely as possible to tax laws.

\section{The Full Cost Method}

The full cost method of accounting was introduced during the mid-1950s (Nichols and Linda, 2012; Dehne, 1983). In contrast to the SE method, under the FC method of accounting for investments in the extractive industries, the costs of acquisition, exploration, evaluation and development are accumulated in a large geographic cost center and capitalized regardless of the outcomes of the exploration activities (PwC, 2017; Ernst \& Young, 2009). These large cost pools are then Depreciated, Depleted and Amortized (DD\&A) over the estimated economic life of the field on a cost center basis (usually geographically) as production occurs (Johnson and Ramanan, 1988; Ernst \&Young, 2009). This method takes the view that in order to find oil and gas reserves companies will experience unsuccessful explorations. These unsuccessful explorations, according to Most (1979), are sort of normal waste that should be capitalized as part of the cost of a product. Hence costs of unsuccessful discoveries attribute indirectly to successful findings. Therefore, costs of both successful and unsuccessful explorations are related to the discovery of reserves. These costs must be capitalized and matched against future revenues instead of expensing them in the period in which they are incurred. Evidence shows that smaller, highly levered and less profitable extractive companies usually use this method because it creates an enhancement effect on earnings (Cortese et al., 2009; Noël et al., 2010; Howard and Harp, 2009; ICAI, 2013). Since the FC method of accounting yield higher net income during the early years of growth, in comparison to SE method, smaller and young-oil and gas companies prefer this method of accounting for their pre-production and exploration expenses. These characteristics of FC companies, according to (Johnson and Ramanan, 1988), "reflect incentives associated with debt covenants that require firms to maintain prescribed levels of certain key financial variables (e.g., interest coverage and leverage ratios and unrestricted retained earnings)." 


\section{Successful Efforts Method Versus Full Cost Method-the Debate}

The main difference between full cost and successful efforts methods is related to their treatment of predevelopment expenditures, specifically expenditures incurred during the Exploration and Evaluation (E\&E) phase of oil and gas investment. While pre-development expenditure is capitalized by full cost companies, this expenditure is capitalized by successful efforts companies only if it leads to commercially viable discoveries. Development expenditure is capitalized by both methods, as companies only develop reserves of mineral resources when they are certain the reserves contain commercially viable resources. Therefore, most of the debate regarding accounting for extractive industries centers on treatments of expenditures during the E\&E stages of investment. For detailed description of the FC and SE methods (McDonald, 1974; Lilien and Pastena, 1981).

While the two methods lead to different figures being reported in both the statement of comprehensive income and the statement of financial position, each of these methods has its proponents and opponents. Much of the debate centers on differing philosophical perspectives with regard to how assets are defined under each method. An asset, as defined by the IASB, is 'a resource controlled by the entity as a result of past events and from which future economic benefits are expected to flow to the entity' (IASB, 2010). On the one hand, under the successful efforts method, the costs of unsuccessful operations do not lead to future economic benefits as defined by IASB (2010) and are therefore expensed in the period in which they are incurred. On the other hand, the philosophy of the full cost method is that all preproduction costs are in fact part of the process of finding mineral resources; some of these costs will not lead directly to a successful discovery, but without them the business cannot be carried out (Flory and Grossman, 1978). Dehne (1983) claims that dry holes for oil and gas companies are similar to waste in manufacturing companies and waste is a normal utilization of resources in these companies. Based on this view, Dehne sees that costs of dry holes and other unsuccessful efforts should be capitalized in a normal utilization of resources as a necessary cost of production. In this context, what is classified as the cost of unsuccessful discoveries under SE method contributes indirectly to the successful finding of mineral resources according to the FC philosophy. Hence, according to the FC method, all related pre-production expenditures must be capitalized as an intangible asset in the balance sheet. In other words, while the successful efforts method considers that future economic benefits are generated only as a result of expenditure on successful discoveries, the full cost method contemplates future economic benefits that arise from total expenditure. Based on this account it can be claimed that the interpretation and application of the "telling it like it is" concept does differ between the two accounting methods and this is obviously not making it easy to stakeholders particularly when it comes to making investment decisions.

Underpinning the debate is conflicting interpretations of the matching concept presented by the proponents of each method. The matching concept is predicated on the assumption that in measuring and reporting profits, revenues should be set against the necessary expenditure that generates them (Thomas and Ward, 2009). The proponents of the successful efforts method, the larger oil and gas producers, argue that the matching concept cannot allow expenditure that does not result in successful discoveries to be recognized in the statement of financial position as an asset and must be written off in the statement of comprehensive income as a period expense (Jones, 2010). In so doing, revenues from specific discoveries, the successful discoveries, are matched with costs that have a direct association with them, such as DD\&A of capitalized expenditure and the general expenses in addition to production costs. In contrast, proponents of the full cost method, smaller oil and gas producers, argue that the costs of unsuccessful discoveries are incurred to generate future revenues and must be matched with revenues from successful discoveries (Jones, 2010). Thus, the necessary expenditure to generate the future revenues is represented by the DD\&A of the total capitalized costs (both successful and unsuccessful) plus the production and other general costs. From this perspective, Bryant (2003) suggests that the full costing method is more consistent with the matching concept and provides measures of assets and earnings that are more consistent with the economic reality of the company.

Given these controversies, our view is that FC method of accounting for oil and gas industries, whilst suitable fit for smaller companies, is not the best fit for reporting oil and gas expenditures. The SE method is more logical and appropriate for accounting for extractive industries in general and oil and gas companies in particular. Therefore, we join the callers for unifying accounting practices for the oil and gas industry based on the SE method philosophy and practices.

\section{Method Choice Effects and the Need for Harmonized Treatment}

A choice of an accounting method allows oil and gas companies to engineer their reported profit and book values of their assets. It is well known that extensive and aggressive exploration activities by oil and gas companies lead to high percentage of unsuccessful discoveries. This results in large sums of costs that are capitalized by FC companies but expensed by SE 
companies. An increase of such unsuccessful costs leads to corrosion in reported profit, book value of assets and an increase in variance of earning by SE companies. Therefore, it is theorized that highly levered oil and gas companies with excessive exploration activities prefer FC accounting method that partially avoid the adverse impact of risky exploration activities on debt covenant restrictions (Johnson and Ramanan, 1988).

Regardless of which side of the debate one takes, the choice of accounting method has implications for how the financial statements are portrayed and it therefore affects the decisions of investors (Abdo, 2016; Misund, 2017). Three implications can be noted here. One, by capitalizing all costs and writing them off in portions of DD\&A against the revenues of the future successful discoveries, the full cost method results in reporting a stronger financial position and better financial performance than the successful efforts method (Johnson and Ramanan, 1988). Therefore, in theory, full cost companies may be seen as stronger performers and find it easier to access external funds than successful efforts companies (Flory and Grossman, 1978). On the other hand, by expensing unsuccessful expenditures (the costs of dry holes) in the year in which they are incurred, the SE method avoids overstating assets and smoothing income for the successful efforts' companies, making them more prudent and, hence, less risky to invest in compared to full costing companies (Bryant, 2003). In addition, by capitalizing unsuccessful costs, the full cost companies only delay loss recognition by deferring the effects of expenses (Flory and Grossman, 1978; ICAI, 2013).

Two, in periods of cutbacks on exploration expenditure, a successful efforts method entity will ease off significant sums of expenses, usually arising from unsuccessful discoveries, from the statement of comprehensive income. In such a case, while the company's investment activities are reduced, the company's financial performance will show a rise in reported profit due to less expenditure being written off compared with previous years of reporting when operations were normal. This significant rise in profit will be felt for a year or two (Ernst \& Young, 2009; Alfredson et al., 2009). This is because significantly less expense (dry holes' costs) will be charged against revenues in the short-term, but for a medium to longer term, this would lead to lesser revenues due to contraction in exploration activities and production. The effects of cutting investments back on full cost companies are immaterial in the short-term compared to those of successful efforts. This is because the statement of comprehensive income of full cost companies will be refreshed by the cut into the DD\&A charges associated with the reduced exploration and evaluation expenditure, but this light effect will only be felt for a number of years to come. This is because reducing exploration activities and cutting exploration expenditure for full costing methods means less DD\&A charges being reported against revenues.

Finally, the profits of a company using successful efforts will be significantly reduced, or a loss may be reported, in a period when such a company may experience more unsuccessful operations due to writing off exploration expenditure. The effects of such a situation will be less detrimental on companies that use the full cost method of accounting due to the capitalization of these expenditures and spreading their negative effects over a number of years in the form of DD\&A charges to the statement of comprehensive income. It is argued that because the full cost method capitalizes every cost and depreciates, depletes and amortizes these costs using the same basis from year to year, a lesser distortion of the annual income will result compared to the successful efforts treatment of the unsuccessful expenditures (PwC, 2017; ICAI, 2013).

\section{Concluding Remarks}

Accounting for oil and gas industry has been and still is, subject to significant controversy. Oil and gas companies use different accounting methods to report their expenditure. This results in incomparable accounting statements' figures and numbers of companies that use different accounting methods. Even within the same accounting method, companies use different accounting practices and this does not allow easy comparison between reporting entities.

International accounting bodies have tried to engineer and implement some solutions that could have reduced these differences and ease the described controversy. The Financial Accounting Standard Board (FASB) attempted to eliminate the full cost method but were not successful. A new accounting method, RRA, was introduced by Securities and Exchange Commissions (SEC) but this was proved to lack practicality (SEC, 1980). A new International Financial Reporting Standard, IFRS 6, was introduced by the International Accounting Standard Board, but this has not been proved to sort out the issue.

Therefore, differences in accounting practices between oil and gas companies have not been eliminated and the controversy continues to stand. This situation seems to have motivate academic writers to advice stakeholders in general and shareholders in particular, to use cash flow statement, rather than income statement and balance sheet, to aid their decision making. Whilst this is unhealthy situation, we call on the International Accounting Standard Board to consider improving the IFRS 6 in ways that eliminate the differences in accounting practices between different methods of accounting. However, even with the existence of such a powerful standard, the effectiveness of it is subject to its implementation by companies that are not forced to use IFRSs in reporting their expenditure. Therefore, the IASB is required to develop a comprehensive accounting 
standard for the oil and gas companies. Upon issuing such a standard, governments, stock markets and other authorities will be required to enforce implementation of this standard. Such efforts would lead to improved comparability of financial statements of oil and gas companies and an ease of decision making process for stakeholders.

\section{Acknowledgement}

We thank Maher Abdo for reviewing this paper and providing comments.

\section{Author's Contributions}

This article contributes to the exsiting literature on accounting for extractive industries and the need for a single accounting standard. The authors make a call on the IASB to engineer an accounting standard the unify accounting practices by oil and gas companies.

\section{Ethics}

This article is mainly written based on literature review and the authors' own experience in the field of accounting for the oil and gas industry. No ethical issues arises as part, or consiqunces of, this article.

\section{References}

Abdo, H., 2016. Accounting for Extractive Industries: has IFRS 6 harmonized accounting practices by extractive industries? Australian Accounting Rev. J., 26: 346-359. DOI: 10.1111/auar.12106

Abdo, H., M. Mangena, G. Needham and D. Hunt, 2017. Provisions for oil and gas decommissioning costs: Compliance with disclosure requirements by oil and gas companies listed in the UK. Published by Institute for Strategic and Sustainable Accounting Development (ISSAD), School of Accountancy, Universiti Utara Malaysia, UUM Sintok, Kedah, Malaysia.

Alfredson, K., K. Leo, R. Picker, J. Loftus and K. Clark, 2009. Applying International Financial Reporting Standards, 2nd Edn., Wiley \& Sons, Australia.

BP Statistical Review of World Energy, 2017.

Christie, S., 2017. The Telegraph Revealed: The world's 10 largest companies by revenue.

Cortese, L.C., L.H. Irvine and A.M. Kaidonis, 2009. Extractive industries accounting and economic consequence: Past, present and future. Accounting Forum, 33: 27-37. DOI: 10.1016/j.accfor.2008.07.005

Dyckman, T.R. and A.J. Smith, 1979. Financial accounting and reporting by oil and gas producing companies: A study of information effects. J. Accounting Economics, 1: 47-75. DOI: $10.1016 / 0165-4101(79) 90014-4$
Ernst \& Young, 2009. US GAAP vs. IFRS- the basic: oil and gas.

Ernst \&Young, 2009. Rule 4-10 of the SEC requires the use of total proven oil and gas reserves as a basis for calculating DD\&A.

Flory, S.M. and S.D. Grossman, 1978. New Oil and gas accounting requirements. CPA J., 48: 39-43.

Gallun, R.A., C.J. Wright, L.M. Nichols and J.W. Stevenson, 2001. Fundamentals of Oil \& Gas Accounting, 4th Edn., Tulsa, PennWell.

Howard, A.W. and A.B. Harp, 2009. Oil and gas company valuations. Bus. Valuation Rev., 28: 30-36. DOI: $10.5791 / 0882-2875-28.1 .30$

IASB, 2010. Discussion paper - extractive Activities IASB, International Accounting Standard Board.

ICAI, 2013. Guidance Note on accounting for Oil and Gas Production Activities, The Institute of Chartered Accountants of India.

Johnson, W.B. and R. Ramanan, 1988. Discretionary Changes from Successful Efforts to Full Cost Methods: 1970-76. Accounting Rev., 63: 96-110.

Jones, B.N., 2010. Intermediate Accounting, 11th Edition, South-Western Cengage Learning USA.

Lilien, S. and V. Pastena, 1981. Intramethod comparability: The case of the oil and gas industry. Accounting Rev., 56: 690-703.

McDonald, R.B., 1974. Comparability of corporate financial statements-petroleum industry. Testimony before the Committee on Interior and Insular Affairs of the United States Senate.

Misund, B., 2017. Accounting method choice and market valuation in the extractive industries. Cogent Economics and Finance.

Most, K.S., 1979. A new method of accounting for oil and gas producers. Management Accounting, 60: 53-57.

17. Dehne, C.A., 1983. Needed: A single accounting method for oil and gas producers. Management Accounting, 65: 52-57.

Nichols, L. and M. Linda, 2012. Has international oil and gas accounting been politicised? Petroleum Accounting Financial Management, 31: 22-34.

Noël, C., G.A. Ayayi and V. Blum, 2010. The European Union's Accounting Policy analyzed from an Ethical Perspective: The case of petroleum resources, prospecting and evaluation. Critical Perspectives Accounting, 21: 329-34.

DOI: 10.1016/j.cpa.2009.11.009

PwC, 2017. Financial Reporting in the Oil and Gas Industry: International Financial Reporting Standards. 3rd Edn. 10. Bryant, L., 2003. Relative value relevance of the successful efforts and full cost accounting methods in the oil and gas industry. Review Accounting Stud., 8: 5-28. DOI: $10.1023 / \mathrm{A}: 1022645521775$ 
Russell, A. and L. Jenkins, 2010. Reflection of the attempt to set a comprehensive international accounting standard for the oil and gas industry. Petroleum Accounting Financial Management J., 29: 16-29.

SEC, 1980. The 46th Annual Report of the Securities and Exchange Commission for the fiscal year ended.
Thomas, A. and M. Ward, 2009. Introduction to Financial Accounting. 6th Ed., McGraw-Hill. London.

Van Riper, R., 1994. Setting standards for financial reporting: FASB and the struggle for control of a critical process. Connecticut. USA. 